\title{
Correction to: Associations of trace elements in blood with the risk of isolated ventricular septum defects and abnormal cardiac structure in children
}

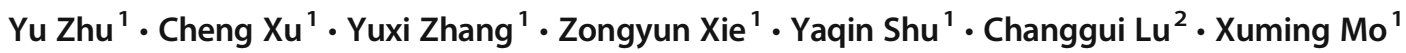

Published online: 17 January 2020

(C) Springer-Verlag GmbH Germany, part of Springer Nature 2020

Correction to: Environmental Science and Pollution Research (2019) 26:10037-10043 https://doi.org/10.1007/s11356-019-04312-0

The original publication of this paper contains an error.

The correct age (month) of controls in Table 1 should be "97.3 \pm 48.7 " and the $\mathrm{P}$ value of age should be " $<0.001$ ".

Publisher's note Springer Nature remains neutral with regard to jurisdictional claims in published maps and institutional affiliations.

The online version of the original article can be found at https://doi.org/ 10.1007/s11356-019-04312-0

Xuming Mo

mohsuming15@sina.com

1 Department of Cardiothoracic Surgery, Children's Hospital of Nanjing Medical University, 72 Guangzhou Road, Nanjing 210008, China

2 Department of Pediatric Surgery, Children's Hospital of Nanjing Medical University, Nanjing, China 